\title{
Clinical significance and therapeutic potential of prostate cancer antigen-1/ALKBH3 in human renal cell carcinoma
}

\author{
KIYOHIKO HOTTA $^{1,6}$, MASAYUKI SHO ${ }^{1}$, KIYOHIDE FUJIMOTO $^{2}$, KEIJI SHIMADA ${ }^{3}$, ICHIRO YAMATO ${ }^{1}$, \\ SATOSHI ANAI ${ }^{2}$, HIROSHI HARADA ${ }^{4}$, KAZUTAKE TSUJIKAWA ${ }^{5}$, NOBORU KONISHI ${ }^{3}$, \\ NOBUO SHINOHARA $^{6}$ and YOSHIYUKI NAKAJIMA ${ }^{1}$
}

\begin{abstract}
Departments of ${ }^{1}$ Surgery, ${ }^{2}$ Urology and ${ }^{3}$ Pathology, Nara Medical University, Kashihara, Nara; ${ }^{4}$ Kidney Transplant Surgery, Sapporo City General Hospital, Sapporo; ${ }^{5}$ Laboratory of Molecular and Cellular Physiology, Graduate School of

Pharmaceutical Sciences, Osaka University, Osaka; ${ }^{6}$ Department of Renal and Genitourinary Surgery, Hokkaido University Graduate School of Medicine, Sapporo, Japan
\end{abstract}

Received March 6, 2015; Accepted April 14, 2015

DOI: $10.3892 /$ or.2015.4017

\begin{abstract}
Prostate cancer antigen-1 (PCA-1)/ALKBH3 has been recently identified in human prostate cancer and its expression is correlated with disease progression and prognosis. However, the precise role and function of PCA-1/ALKBH3 in human malignancies are largely unknown. In the present study, we investigated the clinical significance and therapeutic potential of PCA-1/ALKBH3 in renal cell carcinoma (RCC). PCA-1/ALKBH3 expression was examined by immunohistochemistry in $101 \mathrm{RCC}$ patients who underwent radical or partial nephrectomy. Its expression was positively correlated with advanced pathological $\mathrm{T}$ - and $\mathrm{M}$-factors and TNM stage $(\mathrm{T}, \mathrm{P}<0.05 ; \mathrm{M}, \mathrm{P}<0.01 ; \mathrm{TNM}, \mathrm{P}<0.01$, respectively). In the prognostic analysis, PCA-1/ALKBH3-negative patients with RCC had a significantly better prognosis than PCA-1/ALKBH3-positive patients (5-year survival rate, 92.9 vs. $75.9 \%$, respectively; $\mathrm{P}<0.05)$. Next, the therapeutic potential of targeting PCA-1/ALKBH3 was further evaluated by small interfering RNA method using a human RCC cell line (CAKI-1). We found that PCA-1/ALKBH3 knockdown significantly inhibited the growth of CAKI-1 cells compared with the control $(\mathrm{P}<0.001)$. Furthermore, knockdown of PCA-1 induced apoptosis in CAKI-1 cells, as assessed by poly(ADP-ribose) polymerase-cleavage assays. We demonstrated for the first time that PCA-1/ALKBH3 expression has a significant prognostic impact on patient prognosis in RCC. Furthermore, its knockdown has a therapeutic efficacy on RCC. Taken together, both our clinical and experimental data strongly suggest that PCA-1/ALKBH3 may be functionally important and a novel molecular target for human RCC.
\end{abstract}

Correspondence to: Dr Masayuki Sho, Department of Surgery, Nara Medical University, 840 Shijo-cho, Kashihara, Nara 634-8522, Japan

E-mail: m-sho@naramed-u.ac.jp

Key words: renal cell carcinoma, ALKBH3, PCA-1, apoptosis, prognosis

\section{Introduction}

Renal cell carcinoma (RCC) is the most common type of kidney cancer, and the incidence has been rising steadily. Due to the lack of symptoms at the early stages, approximately one-third of patients present with advanced disease, either locally advanced or metastatic (1,2). Early stage RCC is usually curable by surgery. On the other hand, therapy for recurrent or metastatic tumors still needs to be improved. RCC is generally refractory to conventional anticancer treatments including chemotherapy and radiotherapy. Although immunotherapy remains the effective therapy when treating advanced RCC, long-term outcome has been disappointing $(1,3)$. Furthermore, targeted therapies have been demonstrated to have a significant clinical response and prolong patient survival (4-11). However, these treatments are not effective enough to achieve a complete response and also cause several adverse effects. Therefore, novel approaches against RCC need to be developed to improve patient prognosis.

Prostate cancer antigen-1 (PCA-1) has been identified in human prostate cancer and its expression is associated with disease progression and prognosis $(12,13)$. Furthermore, it was found to be identical to ALKBH3, a member of the human AlkB homologs. In Escherichia coli (E. coli), the alkB gene product was identified as a protein which carries out DNA repair by oxidative demethylation and repairs both DNA and RNA methylation (14-16). Nine AlkB homologs have been identified in human tissues (17-20). Among these human AlkB homologs, PCA-1/ALKBH3 has been reported to have a protein structure and catalytic mechanisms of repairing DNA and RNA quite similar to E. coli AlkB (17-24). In addition to these physiological roles of PCA-1/ALKBH3 in humans, recent studies have demonstrated that PCA-1/ALKBH3 is highly expressed and associated with poor disease outcome in several human types of cancers including prostate, non-small cell lung and pancreatic cancer $(12,13,25,26)$. However, the precise functions and clinical significance of PCA-1/ALKBH3 are still largely unknown.

The aim of the present study was to investigate the clinical importance of PCA-1/ALKBH3 in human RCC. Furthermore, 
we also aimed to clarify its therapeutic potential using siRNA knockdown method.

\section{Materials and methods}

Patients. We analyzed 101 patients with RCC, who received radical or partial nephrectomy from 2003 to 2008 at Nara Medical University Hospital. The age of the patients ranged from 31 to 84 years (median 66 years), and the male to female ratio was 2.6:1.0. None of these patients received preoperative anticancer treatments including immunotherapy and arterial embolization therapy. They were histopathologically composed of 81 cases $(80 \%)$ of clear cell type, 9 cases $(9 \%)$ of granular cell type, 4 cases (4\%) of papillary cell type, 4 cases (4\%) of spindle cell type, 2 cases $(2 \%)$ of cystic cell type and 1 case $(1 \%)$ of mixed clear and spindle type. The tumor stage was classified according to the UICC TNM classification of renal tumors (27). Pathological grades were assigned according to the criteria proposed by Fuhrman et al (28). The present study was approved by the Ethics Review Committee of Nara Medical University Hospital.

Preparation of antisera. Anti-PCA-1/ALKBH3 antisera were prepared as previously described against a synthetic PCA-1/ALKBH3 peptide (amino acids 64-76) as the antigen (13). After a 0.5-mg aliquot of peptides was emulsified and injected into rabbits, blood was collected at 2-week intervals. The relative activity of the antisera against the synthetic peptide was tested by enzyme-linked immunosorbent assay.

Immunohistochemistry. Immunohistochemical staining for PCA-1/ALKBH3 was performed with a Dako Envision ${ }^{\mathrm{TM}}$ kit (Dako, Tokyo, Japan). Formalin-fixed, paraffin-embedded tissues were cut into 5- $\mu \mathrm{m}$ sections, deparaffinized and rehydrated in a graded series of ethanols. Antigen retrieval was carried out by heating the tissue sections using a target retrieval solution, pH 9.0 (Dako). Then, the samples were incubated for 5 min in peroxidase blocking solution (Dako) to inhibit endogenous peroxidase. The sections were then incubated overnight at $4^{\circ} \mathrm{C}$ with anti-human PCA-1/ALKBH3. A subsequent reaction was carried out using secondary antibodies (Dako) at $37^{\circ} \mathrm{C}$ for $30 \mathrm{~min}$. Then, the sections were washed three times with phosphate-buffered saline, and subsequently the color was displayed with diaminobenzidine (DAB) (Dako) for $\sim 5 \mathrm{~min}$. Sections were counterstained with hematoxylin, dehydrated in ethanol, cleared in xylene and coverslipped.

Evaluation of the immunostaining. Evaluation of the immunostaining was performed by a consensus of two pathologists blinded to the clinicopathological data. The staining intensity was graded on a scale of 0 to 2 ( 0 , no staining; 1 , weak staining; and 2, strong staining). Specimens in which one or more tumor areas with different staining intensities were present were scored for the most prevalent intensity. The PCA-1/ALKBH3 expression level was divided into two categories: low (scale 0-1) and high (scale 2) expression.

Cell culture and reagents. The human RCC line, CAKI-1, was obtained from the American Type Culture Collection (ATCC; Manassas, VA, USA). The CAKI-1 cells were grown in RPMI-1640, supplemented with $10 \%$ heat-inactivated fetal bovine serum and incubated at $37^{\circ} \mathrm{C}$ in a humidified atmosphere of $5 \% \mathrm{CO}_{2}$ in air. Anti-poly(ADP-ribose) polymerase (PARP) and anti-caspase 3 antibodies were purchased from Cell Signaling Technology (Beverly, MA, USA); anti-actin antibodies were purchased from Santa Cruz Biotechnology (Santa Cruz, CA, USA).

Transfection of ALKBH3 siRNA. For our transfection analyses, CAKI-1 cells were seeded in 6-well plates and transfected either with the control RNA (Santa Cruz Biotechnology) or with $100 \mathrm{nmol} / 1$ of the siRNA of PCA-1/ALKBH3. Transfections were carried out using the Lipofectamine system (Invitrogen, Tokyo, Japan) in accordance with the manufacturer's protocol when cells achieved $\sim 30 \%$ confluency. The PCA-1/ALKBH3 siRNA duplexes, generated with 30-dTdT overhangs and prepared by Qiagen (Tokyo, Japan), were chosen against the DNA target sequences as follows: PCA-1/ALKBH3 (1) target sequence, 5'-CAGAGAGGATA TAACTTATCA-3' and (PCA-1/ALKBH3 (2) target sequence, 5'-ATCGCTATCATCTTTAGGCAA-3'.

Reverse transcription-polymerase chain reaction. Total RNA was extracted using TRIzol reagent and subjected to reverse transcription (RT) and polymerase chain reaction (PCR) using a One-Step RT-PCR kit (Qiagen) according to the manufacturer's protocol. The PCR conditions were $95^{\circ} \mathrm{C}$ for $30 \mathrm{sec}, 55-60^{\circ} \mathrm{C}$ for $30 \mathrm{sec}$ and $72^{\circ} \mathrm{C}$ for $1 \mathrm{~min}$, for a total of 35 cycles. The PCR primers were: PCA-1/ALKBH3 forward, 5'-TACCACTGCTAAGAGCCATCTCC-3'; PCA-1 reverse, 5'-ACCTGCTGAGGTTCTTTGAACAC-3'; glyceraldehyde-3-phosphate dehydrogenase (G3PDH) forward, 5'-ACCACAGTCCATGCCATCAC-3' and G3PDH reverse, 5'-TCCACCACCCTGTTGCTGTA-3'. The PCR products were analyzed on a $1.5 \%$ agarose gel and visualized by ethidium bromide staining.

Real-time reverse transcription-polymerase chain reaction. Total RNA was isolated from the cells using RNAspin Mini (GE Healthcare, Tokyo, Japan). cDNA was synthesized from $1 \mu \mathrm{g}$ RNA using a High Capacity cDNA Reverse Transcription kit (Applied Biosystems, Foster City, CA, USA) following a standard protocol. Specific TaqMan primers and probes were obtained from Applied Biosystems. cDNA was amplified in TaqMan ${ }^{\circledR}$ Fast Universal PCR Master Mix with gene-specific primers and probe on the StepOnePlus ${ }^{\mathrm{TM}}$ Real-Time PCR System. Expression of the gene was normalized against mRNA expression of the housekeeping gene $\beta 2$-microglobulin. Real-time PCR experiments for each gene were performed for three independent experiments.

Western blot analysis. We resolved the cell lysates from the CAKI-1 cells on SDS polyacrylamide gels and transferred them onto polyvinylidene difluoride membranes (Millipore, Bedford, MA, USA), which were blocked in 5\% skimmed milk at room temperature for $1 \mathrm{~h}$. The membranes were then incubated with each of the antibodies described in the previous section for $1 \mathrm{~h}$, followed by incubation with horseradish peroxidase-conjugated anti-mouse or anti-rabbit $\mathrm{IgG}$ (Amersham Pharmacia Biotech, Piscataway, NJ, USA). We 
detected peroxidase activity on X-ray film using an enhanced chemiluminescence detection system.

Cell proliferation assay. The 3-(4,5-dimethylthiazol-2-yl)5-(3-carboxymethoxypheny-1)-2-(4-sulfophenyl)-2H-tetrazolium, inner salt (MTS) assay was used for evaluation of cell proliferation. Aliquots of $2 \times 10^{3}$ cells/well were cultured in 96-well plates. After $72 \mathrm{~h}$, the MTS assay was performed using CellTiter 96 Aqueous One Solution (Promega, Madison, WI, USA) following the manufacturer's instructions.

Statistical analysis. Comparisons among the clinicopathological features were evaluated using $\chi^{2}$ and Fisher's exact tests as appropriate. Statistical significance between two groups of parametric data was evaluated using an unpaired Student's t-test. Survival curves were estimated using the Kaplan-Meier method, and the significance of differences between survival curves was determined using log-lank test. All tests were two-sided, and $\mathrm{P}<0.05$ was considered to indicate a statistically significant result.

\section{Results}

PCA-1/ALKBH3 expression in RCC. First, we evaluated the PCA-1/ALKBH3 expression in actual human RCC tissues. Surgical specimens from 101 RCC patients were examined by immunohistochemistry. The protein expression of PCA-1/ALKBH3 was observed mainly in the cytoplasm of tumor cells (Fig. 1). PCA-1/ALKBH3 expression was detected in 55 of the 101 RCC specimens. Of these, 11 (10.9\%) were weakly positive and $44(43.6 \%)$ were strongly positive. Forty-six specimens $(45.5 \%)$ exhibited negative staining.

Associations between PCA-1/ALKBH3 status and the clinicopathological factors. According to the intensity of the immunohistochemical staining for PCA-1/ALKBH3, 101 specimens were divided into two categories: low (scale 0-1, $\mathrm{n}=57$ ) and high (scale 2, n=44) expression. The associations between PCA-1/ALKBH3 expression and various clinicopathological factors are shown in Table I. The expression of PCA-1/ALKBH3 was positively correlated with advanced pathological T- and M-factors and TNM stage $(\mathrm{P}=0.025,0.012$ and 0.006 , respectively). Furthermore, the increased pre-operative serum $\mathrm{C}$-reactive protein (CRP) levels, which are known to be a negative prognostic factor, were significantly correlated with the PCA-1/ALKBH3 status $(\mathrm{P}<0.001)$. In contrast, there were no significant correlations of PCA-1/ALKBH3 expression with age, gender, Eastern Cooperative Oncology Group Performance Status (ECOG-PS), N-factor, nuclear grade, histology, hemoglobin $(\mathrm{Hb})$, lactate dehydrogenese $(\mathrm{LDH})$ or corrected Ca level.

Patient prognosis. At the time of analysis, 13 out of 101 patients died due to RCC. The median (range) time to death was 12.5 (2-23.4) months. The estimated cancer-specific survival rate 5 years after surgery was $85.9 \%$. Patients with low PCA-1/ALKBH3 expression had a significantly better prognosis than patients with high expression (5-year survival rate, 92.9 vs. $75.9 \%$; $\mathrm{P}<0.05$; Fig. $2 \mathrm{~A}$ ). Moreover, 21 patients had a metastatic lesion at the time of surgery and 13 patients
Table I. Clinicopathological characteristics of the RCC cases according to PCA-1 tumor expression.

\begin{tabular}{|c|c|c|c|}
\hline & $\begin{array}{l}\text { PCA-1 low } \\
\quad(n=57)\end{array}$ & $\begin{array}{l}\text { PCA-1 high } \\
\quad(n=44)\end{array}$ & P-value \\
\hline Age at surgery (years) & $63.7 \pm 11.6$ & $63.2 \pm 11.4$ & 0.84 \\
\hline \multicolumn{4}{|l|}{ Gender } \\
\hline Female & 15 & 13 & \multirow[t]{2}{*}{0.82} \\
\hline Male & 42 & 31 & \\
\hline \multicolumn{4}{|l|}{ ECOG-PS } \\
\hline 0 & 23 & 19 & \multirow[t]{3}{*}{0.30} \\
\hline 1 & 28 & 20 & \\
\hline 2 & 6 & 5 & \\
\hline \multicolumn{4}{|l|}{ T stage } \\
\hline $\mathrm{pT} 1$ & 39 & 26 & \multirow[t]{4}{*}{0.025} \\
\hline pT2 & 2 & 8 & \\
\hline pT3 & 16 & 8 & \\
\hline pT4 & 0 & 2 & \\
\hline \multicolumn{4}{|l|}{$\begin{array}{l}\text { Lymph node } \\
\text { involvement }\end{array}$} \\
\hline Absent & 53 & 39 & \multirow[t]{2}{*}{0.50} \\
\hline Present & 4 & 5 & \\
\hline \multicolumn{4}{|l|}{ Distant metastases } \\
\hline Absent & 53 & 32 & \multirow[t]{2}{*}{0.012} \\
\hline Present & 4 & 12 & \\
\hline \multicolumn{4}{|l|}{ TNM stage } \\
\hline I & 40 & 26 & \multirow[t]{4}{*}{0.006} \\
\hline II & 0 & 2 & \\
\hline III & 12 & 3 & \\
\hline IV & 5 & 13 & \\
\hline \multicolumn{4}{|l|}{ Nuclear grade } \\
\hline 1 & 28 & 14 & \multirow[t]{3}{*}{0.19} \\
\hline 2 & 22 & 21 & \\
\hline $3+4$ & 7 & 9 & \\
\hline \multicolumn{4}{|l|}{ Histology } \\
\hline Clear cell & 49 & 32 & \multirow[t]{2}{*}{0.13} \\
\hline Non-clear cell & 8 & 12 & \\
\hline Hemoglobin (mg/dl) & $13.8 \pm 1.6$ & $13.3 \pm 2.2$ & 0.26 \\
\hline $\begin{array}{l}\text { Lactate dehydrogenese } \\
\text { (IU/1) }\end{array}$ & $190 \pm 39$ & $194 \pm 48$ & 0.65 \\
\hline Corrected Ca (mg/dl) & $9.4 \pm 0.5$ & $9.5 \pm 0.5$ & 0.17 \\
\hline $\begin{array}{l}\text { C-reactive protein } \\
(\mathrm{mg} / \mathrm{dl})\end{array}$ & $0.84 \pm 0.27$ & $2.34 \pm 0.69$ & 0.001 \\
\hline
\end{tabular}

ECOG-PS, Eastern Cooperative Oncology Group Performance Status; PCA-1, prostate cancer antigen-1.

developed metastasis after surgery in the present study. In these metastatic patients, 17 patients $(50 \%)$ were classified in the PCA-1/ALKBH3 high group. According to Memorial Sloan-Kettering Cancer Center (MSKCC) risk classification 


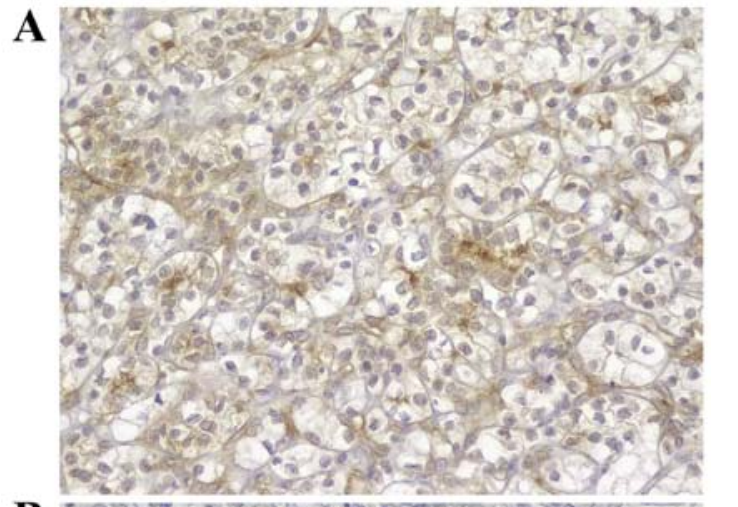

B

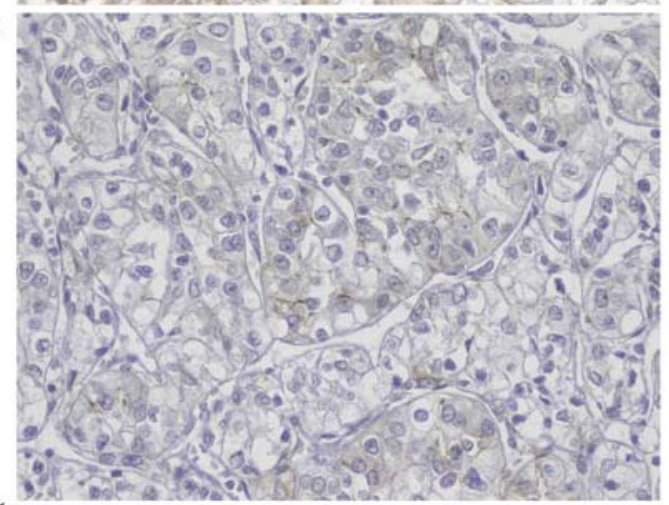

C

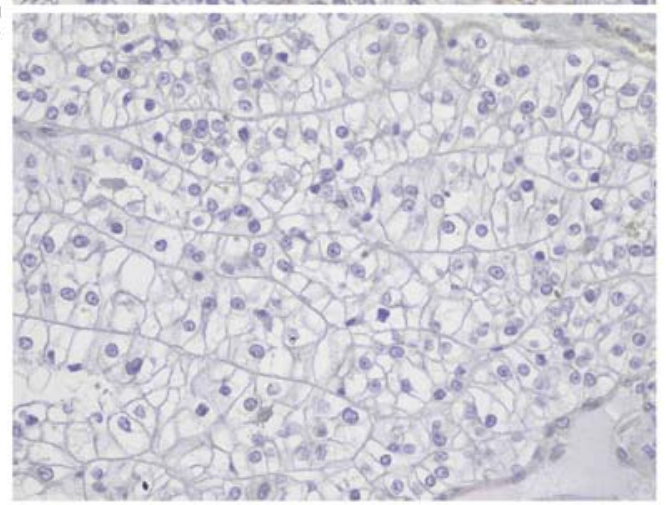

Figure 1. Immunohistochemical staining of PCA-1/ALKBH3 expression in renal cell carcinoma tissues. Representative case of tumors with (A) strong expression, (B) weak expression and (C) negative expression of PCA-1/ ALKBH3. Original magnification, x400. PCA-1, prostate cancer antigen-1.

(29), 29 patients $(85 \%)$ were defined in the intermediate risk group, while $1(3 \%)$ and $4(12 \%)$ patients were defined in the favorable and poor risk groups, respectively. The metastatic patients with low PCA-1/ALKBH3 expression had a significantly better survival than those with high expression (5-year survival rate, 82.4 vs. $39.2 \%$; $\mathrm{P}<0.05$; Fig. 2B).

Effect of small interfering RNA knockdown of PCA-1/ALKBH3 in RCC cells. We investigated the therapeutic efficacy of targeting PCA-1/ALKBH3 in a human RCC cell line, CAKI-1. To this end, we employed conventional small interfering RNA (siRNA) knockdown method. We first confirmed the PCA-1/ALKBH3 protein and gene expression in the CAKI-1 cells using western blotting, RT-PCR and real-time RT-PCR analysis. These data indicated that PCA-1/ALKBH3 gene expression was successfully depleted by $100 \mathrm{nM}$ siRNA transfection and culture for $72 \mathrm{~h}$ (Fig. 3A-C). In the MTS assay,
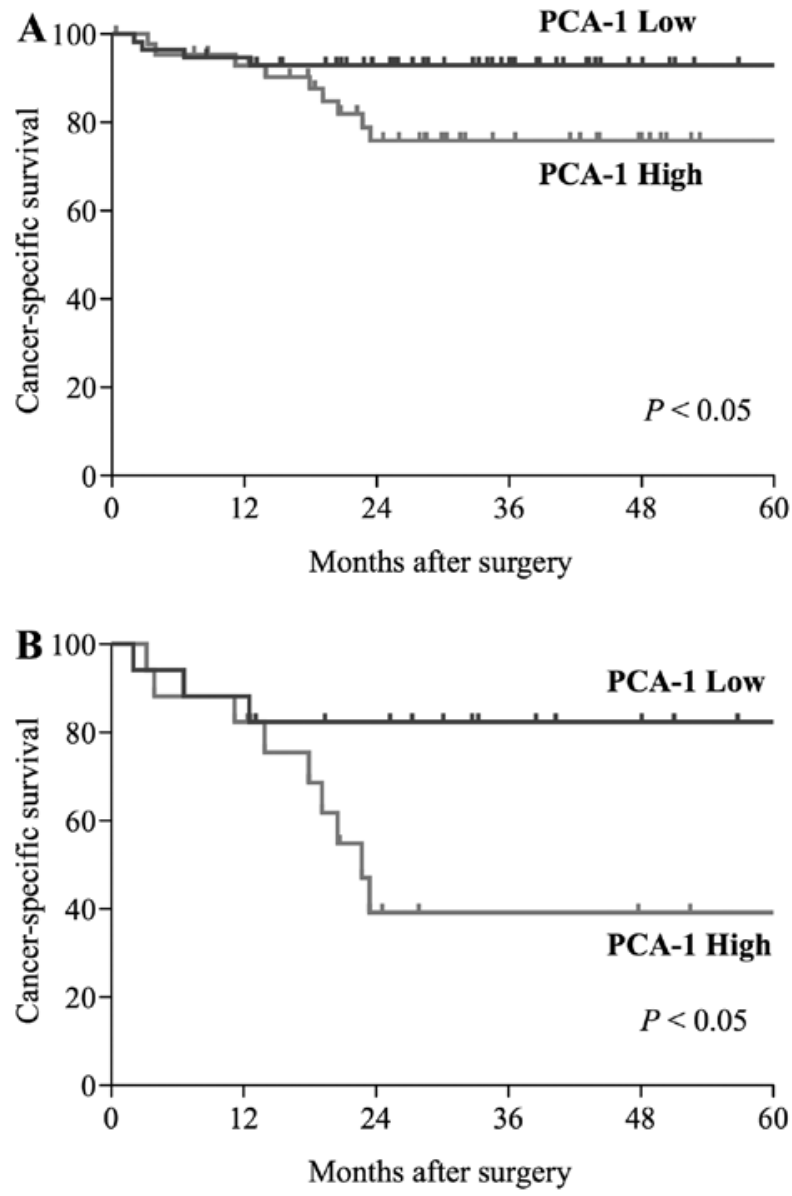

Figure 2. (A) Kaplan-Meier survival analysis of cancer-specific survival of all patients according to PCA-1/ALKBH3 tumor expression. Patients with low PCA-1/ALKBH3 expression $(n=57)$ had a significantly better prognosis than patients with high expression $(n=44)$. (B) Kaplan-Meier survival analysis of cancer-specific survival of metastatic patients according to PCA-1/ALKBH3 tumor expression. Patients with low PCA-1/ALKBH3 expression $(n=17)$ had a significantly better prognosis than patients with high expression $(n=17)$. PCA-1, prostate cancer antigen-1.

we found that siRNA-mediated depletion of PCA-1/ALKBH3 significantly inhibited the growth of CAKI-1 cells compared with that in the control (Fig. 3D, $\mathrm{P}<0.001$ ). There was $48 \%$ inhibition in CAKI-1 cell growth.

PCA-1/ALKBH3 knockdown induces apoptosis in RCC cells. Furthermore, we evaluated apoptosis using PARP-cleavage analysis. As a result, PCA-1/ALKBH3 knockdown induced apoptosis in the CAKI-1 cells (Fig. 4). We also observed the cleavage of caspase-3 (Fig. 4). The results suggest that PCA-1/ALKBH3 protects renal cancer cells from mitochondrial pathway-mediated apoptosis.

\section{Discussion}

Humans are continuously exposed to agents that methylate DNA and RNA. Such agents initiate abnormal methylation on genes. When DNA methylation is dysregulated, the harmful methylation contributes to several disease conditions including cancer. Therefore, the enzymatic functions of repairing these abnormalities are critical for maintaining DNA and RNA 
$\mathbf{A}$

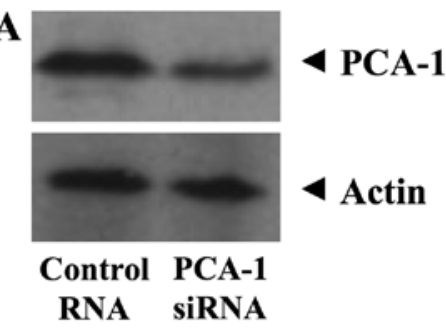

C

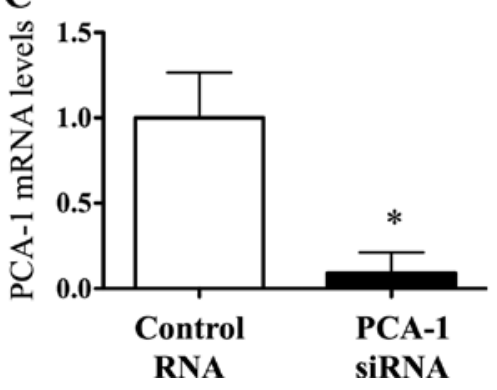

B

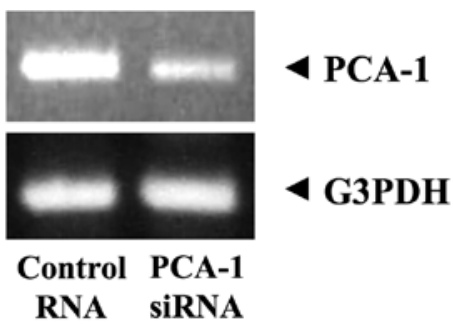

D

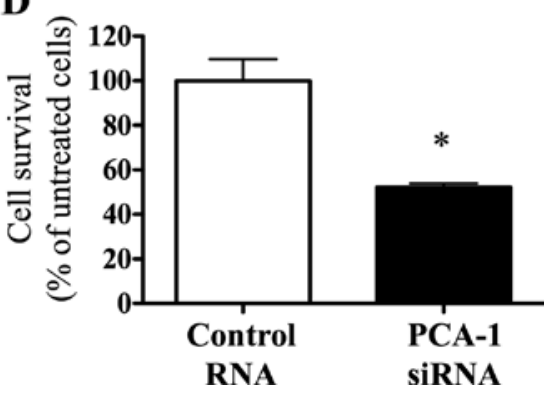

Figure 3. Inhibition of PCA-1/ALKBH3 expression by siRNA decreases cell proliferation in vivo. CAKI-1 cells were transfected with the control or siRNA of PCA-1/ALKBH3. After $72 \mathrm{~h}$ of incubation, protein and mRNA levels of PCA-1/ALKBH3 were examined. (A) The protein and (B) mRNA expression of PCA-1/ALKBH3 was successfully suppressed in the CAKI-1 cells. (C) PCA-1/ALKBH3 mRNA expression was significantly reduced following transfection with PCA-1/ALKBH3 siRNA ( $\mathrm{n}=4$ of each group). (D) After $72 \mathrm{~h}$ of incubation, cell proliferation was determined by MTS assay. Cell proliferation was significantly suppressed by PCA-1/ALKBH3 gene silencing ( $\mathrm{n}=6$ of each group). The results are representative of three independent experiments. Data are presented as means \pm SD. ${ }^{*} \mathrm{P}<0.001$. PCA-1, prostate cancer antigen-1.
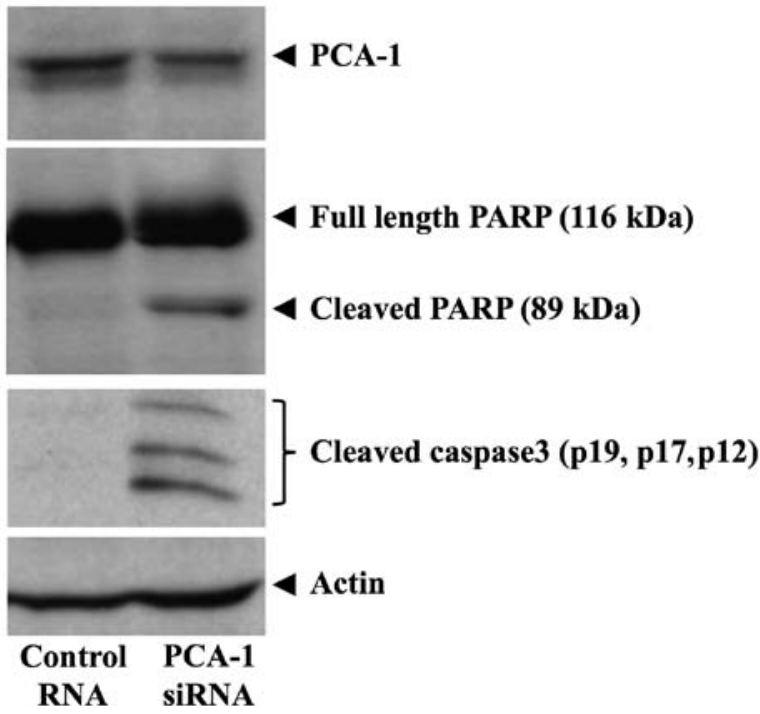

Figure 4. Inhibition of PCA-1/ALKBH3 expression by siRNA induces apoptosis in vivo. CAKI-1 cells were transfected with the control or siRNA of PCA-1/ALKBH3. After $72 \mathrm{~h}$ of incubation, protein expression of PCA-1/ALKBH3, full-length and cleaved poly(ADP-ribose) polymerase (PARP) and cleaved caspase-3 were examined by western blotting. PCA-1/ALKBH3 gene silencing induced apoptosis in the CAKI-1 cells, as demonstrated by appearance of cleaved PARP and cleaved caspase-3. PCA-1, prostate cancer antigen-1.

integrity. It has been reported that $\mathrm{AlkB}$ proteins play an important roles in the demethylation of DNA (14-16). At least 9 AlkB homologs (ALKBH1-8, FTO) have been identified in human tissues (17-20). Among the diverse functions of the AlkB family, there are only limited number of studies that have described its role in cancer biology. For example,
ALKBH8 was reported to contribute to the progression of human bladder cancer (30). Another study showed that ALKBH2 knockdown enhanced the sensitivity of human lung cancer cells to cisplatin-based chemotherapy (31). In contrast, the overexpression of ALKBH2 was found to inhibit the cell growth in gastric cancer (32). Taken together, each AlkB family member has distinctive role and exerts various functions in each type of cancer.

Among the human AlkB homologs, ALKBH3 is known as a unique member which demethylates RNA besides repairing methylated DNA. In tumors, PCA-1/ALKBH3 has originally been identified in human prostate cancer $(12,13)$. PCA-1/ALKBH3 has been shown to significantly contribute to the tumor growth and clinical outcome in several types of cancers including not only prostate, but also lung and pancreatic cancer $(25,26)$. Furthermore, PCA-1/ALKBH3 was also reported to be one of the candidate gene associated with the risk of papillary thyroid cancer (33). In contrast, it has been reported that PCA-1/ALKBH3 plays a protective role in chronic inflammation-associated colon carcinogenesis (34). Taken together, the precise role of PCA-1/ALKBH3 in human types of cancers remains to be fully elucidated. Since there is no report to address the roles of the AlkB family in $\mathrm{RCC}$, we investigated the clinical significance of PCA-1/ALKBH3 in RCC.

First, we found that PCA-1/ALKBH3 protein was expressed in approximately half of the RCC tissues. Furthermore, we also found that intense PCA-1/ALKBH3 expression was significantly associated with advanced pathological T-factor, TNM stage and distant metastasis in the RCC cases. Our previous study showed no association between PCA-1/ALKBH3 expression and distant metastasis in pancreatic cancer (25). Therefore, in contrast to pancreatic cancer, the present study suggests that 
PCA-1/ALKBH3 plays a critical role in tumor metastasis as well as progression in human RCC. Importantly, patients with high PCA-1/ALKBH3 expression had a significantly poorer prognosis than patients with low PCA-1/ALKBH3 expression. Furthermore, we also evaluated PCA-1/ALKBH3 expression in 34 metastatic patients. Notably, although most metastatic patients in the present study were classified as an intermediate risk by the MSKCC classification, there was a significant difference in the cancer-specific survival rate between the PCA-1/ALKBH3 high and low group. These clinical data suggest that PCA-1/ALKBH3 may be functionally important in RCC. However, to confirm our preliminary findings, further large-scale studies are required.

Next, we examined the biological roles of PCA-1/ALKBH3 in RCC using siRNA method. Our data indicated that siRNA-mediated knockdown of PCA-1/ALKBH3 resulted in the significant reduction of human renal cancer cell growth. This was consistent with previous data on pancreatic and lung cancer $(25,26)$. The data suggest that PCA-1/ALKBH3 significantly contributes to tumor progression in several human types of cancers. Furthermore, we used the PARP-cleavage assay in order to evaluate the effect of PCA-1/ALKBH3 blockade on the apoptosis of renal cancer cell. We found that inhibition of PCA-1/ALKBH3 induced mitochondrial pathway-mediated apoptosis in the RCC cells. This was also consistent with previous studies on prostate and pancreatic cancer cells $(12,13,25)$. However, in contrast, PCA-1/ALKBH3 knockdown suppressed cell proliferation through p21/p27 mediated cell cycle arrest, yet did not induce apoptosis in human lung cancer cells (26). Other mechanisms may be involved in tumors associated with PCA-1/ALKBH3 expression. We previously reported that PCA-1/ALKBH3 silencing downregulated VEGF expression and inhibited angiogenesis in pancreatic cancer (25). Similarly, angiogenesis was suppressed by PCA-1/ALKBH3 gene silencing in urothelial carcinoma (35). Therefore, we evaluated the correlation between VEGF expression and PCA-1/ALKBH3 in RCC. However, there was no difference in VEGF expression between the RCC cells treated with PCA-1/ALKBH3 siRNA and those with control RNA (data not shown). Taken together, PCA-1/ALKBH3 contributes to tumor progression through distinct mechanisms in each type of human cancer.

Finally, we found that preoperative CRP levels were positively associated with expression of PCA-1/ALKBH3. In contrast, there were no significant correlations of PCA-1/ALKBH3 expression with other factors including $\mathrm{Hb}$, $\mathrm{LDH}$ or corrected $\mathrm{Ca}$ level. CRP is well known as an indicator of systemic inflammatory response. Previous studies showed that increased CRP levels predict poor survival in patients with both localized and metastatic RCC (36-38). We confirmed that the patients with a high CRP level had a significantly poorer prognosis than patients with a normal CRP level in the present study (data not shown). More recently, studies found that CRP plays a functionally important role in the proliferation of tumor cells through various mechanisms including the protection of cancer cells from apoptosis $(39,40)$. Although the underlying mechanism of the positive association between CRP level and PCA-1/ALKBH3 is still unrevealed, further studies are warranted to clarify the fundamental tumor biology and to explore a novel therapeutic strategy.
In conclusion, we demonstrated for the first time that PCA-1/ALKBH3 tumor expression has a significant impact on patients with RCC. Since our data suggest that PCA-1/ALKBH3 may play a functionally important role in RCC, it may be a novel therapeutic target as well as a useful marker for human RCC.

\section{References}

1. Motzer RJ, Mazumdar M, Bacik J, Berg W, Amsterdam A and Ferrara J: Survival and prognostic stratification of 670 patients with advanced renal cell carcinoma. J Clin Oncol 17: 2530-2540, 1999.

2. Cohen HT and McGovern FJ: Renal-cell carcinoma. N Engl J Med 353: 2477-2490, 2005.

3. Yang JC, Sherry RM, Steinberg SM, Topalian SL, Schwartzentruber DJ, Hwu P, Seipp CA, Rogers-Freezer L, Morton KE, White DE, et al: Randomized study of high-dose and low-dose interleukin-2 in patients with metastatic renal cancer. J Clin Oncol 21: 3127-3132, 2003.

4. Motzer RJ, Escudier B, Oudard S, Hutson TE, Porta C, Bracarda S, Grünwald V, Thompson JA, Figlin RA, Hollaender N, et al; RECORD-1 Study Group: Efficacy of everolimus in advanced renal cell carcinoma: A double-blind, randomised, placebo-controlled phase III trial. Lancet 372: 449-456, 2008.

5. Motzer RJ, Hutson TE, Tomczak P, Michaelson MD, Bukowski RM, Oudard S, Negrier S, Szczylik C, Pili R, Bjarnason GA, et al: Overall survival and updated results for sunitinib compared with interferon alfa in patients with metastatic renal cell carcinoma. J Clin Oncol 27: 3584-3590, 2009.

6. Rini BI, Escudier B, Tomczak P, Kaprin A, Szczylik C, Hutson TE, Michaelson MD, Gorbunova VA, Gore ME, Rusakov IG, et al: Comparative effectiveness of axitinib versus sorafenib in advanced renal cell carcinoma (AXIS): A randomised phase 3 trial. Lancet 378: 1931-1939, 2011.

7. Escudier B, Eisen T, Stadler WM, Szczylik C, Oudard S, Staehler M, Negrier S, Chevreau C, Desai AA, Rolland F, et al: Sorafenib for treatment of renal cell carcinoma: Final efficacy and safety results of the phase III treatment approaches in renal cancer global evaluation trial. J Clin Oncol 27: 3312-3318, 2009.

8. Escudier B, Pluzanska A, Koralewski P, Ravaud A, Bracarda S, Szczylik C, Chevreau C, Filipek M, Melichar B, Bajetta E, et al; AVOREN Trial investigators: Bevacizumab plus interferon alfa-2a for treatment of metastatic renal cell carcinoma: A randomised, double-blind phase III trial. Lancet 370: 2103-2111, 2007.

9. Hudes G, Carducci M, Tomczak P, Dutcher J, Figlin R, KapoorA, Staroslawska E, Sosman J, McDermott D, Bodrogi I, et al; Global ARCC Trial: Temsirolimus, interferon alfa, or both for advanced renal-cell carcinoma. N Engl J Med 356: 2271-2281, 2007.

10. Sternberg CN, Davis ID, Mardiak J, Szczylik C, Lee E, Wagstaff J, Barrios CH, Salman P, Gladkov OA, Kavina A, et al: Pazopanib in locally advanced or metastatic renal cell carcinoma: Results of a randomized phase III trial. J Clin Oncol 28: 1061-1068, 2010.

11. Albiges L, Choueiri T, Escudier B, Galsky M, George D, Hofmann F, Lam T, Motzer R, Mulders P, Porta C, et al: A systematic review of sequencing and combinations of systemic therapy in metastatic renal cancer. Eur Urol 67: 100-110, 2015.

12. Shimada K, Nakamura M, Ishida E, Higuchi T, Yamamoto $H$, Tsujikawa K and Konishi N: Prostate cancer antigen-1 contributes to cell survival and invasion though discoidin receptor 1 in human prostate cancer. Cancer Sci 99: 39-45, 2008.

13. Konishi N, Nakamura M, Ishida E, Shimada K, Mitsui E, Yoshikawa R, Yamamoto $\mathrm{H}$ and Tsujikawa K: High expression of a new marker PCA-1 in human prostate carcinoma. Clin Cancer Res 11: 5090-5097, 2005.

14. Aas PA, Otterlei M, Falnes PO, Vågbø CB, Skorpen F, Akbari M, Sundheim O, Bjørås M, Slupphaug G, Seeberg E, et al: Human and bacterial oxidative demethylases repair alkylation damage in both RNA and DNA. Nature 421: 859-863, 2003.

15. Falnes PO, Johansen RF and Seeberg E: AlkB-mediated oxidative demethylation reverses DNA damage in Escherichia coli. Nature 419: 178-182, 2002.

16. Dinglay S, Trewick SC, Lindahl T and Sedgwick B: Defective processing of methylated single-stranded DNA by E. coli AlkB mutants. Genes Dev 14: 2097-2105, 2000. 
17. Tsujikawa K, Koike K, Kitae K, Shinkawa A, Arima H, Suzuki T, Tsuchiya M, Makino Y, Furukawa T, Konishi N, et al: Expression and sub-cellular localization of human ABH family molecules. J Cell Mol Med 11: 1105-1116, 2007.

18. Chen B, Liu H, Sun X and Yang CG: Mechanistic insight into the recognition of single-stranded and double-stranded DNA substrates by ABH2 and ABH3. Mol Biosyst 6: 2143-2149, 2010.

19. Gerken T, Girard CA, Tung YC, Webby CJ, Saudek V, Hewitson KS, Yeo GS, McDonough MA, Cunliffe S, McNeill LA, et al: The obesity-associated FTO gene encodes a 2-oxoglutarate-dependent nucleic acid demethylase. Science 318: 1469-1472, 2007.

20. Kurowski MA, Bhagwat AS, Papaj G and Bujnicki JM: Phylogenomic identification of five new human homologs of the DNA repair enzyme AlkB. BMC Genomics 4: 48, 2003.

21. Ougland R, Zhang CM, Liiv A, Johansen RF, Seeberg E, Hou YM, Remme J and Falnes PO: AlkB restores the biological function of mRNA and tRNA inactivated by chemical methylation. Mol Cell 16: 107-116, 2004.

22. Sundheim O, Vågbø CB, Bjørås M, Sousa MM, Talstad V, Aas PA, Drabløs F, Krokan HE, Tainer JA and Slupphaug G: Human $\mathrm{ABH} 3$ structure and key residues for oxidative demethylation to reverse DNA/RNA damage. EMBO J 25: 3389-3397, 2006.

23. Yu B, Edstrom WC, Benach J, Hamuro Y, Weber PC, Gibney BR and Hunt JF: Crystal structures of catalytic complexes of the oxidative DNA/RNA repair enzyme AlkB. Nature 439: 879-884, 2006.

24. Hausinger RP: FeII/alpha-ketoglutarate-dependent hydroxylases and related enzymes. Crit Rev Biochem Mol Biol 39: 21-68, 2004.

25. Yamato I, Sho M, Shimada K, Hotta K, Ueda Y, Yasuda S, Shigi N, Konishi N, Tsujikawa K and Nakajima Y: PCA-1/ALKBH3 contributes to pancreatic cancer by supporting apoptotic resistance and angiogenesis. Cancer Res 72: 4829-4839, 2012.

26. Tasaki M, Shimada K, Kimura H, Tsujikawa K and Konishi N: ALKBH3, a human AlkB homologue, contributes to cell survival in human non-small-cell lung cancer. Br J Cancer 104: 700-706, 2011.

27. Guinan P, Sobin LH, Algaba F, Badellino F, Kameyama S, MacLennan $G$ and Novick A; Union International Contre le Cancer (UICC) and the American Joint Committee on Cancer (AJCC): TNM staging of renal cell carcinoma: Workgroup No. 3. Cancer 80: 992-993, 1997.

28. Fuhrman SA, Lasky LC and Limas C: Prognostic significance of morphologic parameters in renal cell carcinoma. Am J Surg Pathol 6: 655-663, 1982.

29. Motzer RJ, Bacik J, Murphy BA, Russo P and Mazumdar M: Interferon-alfa as a comparative treatment for clinical trials of new therapies against advanced renal cell carcinoma. J Clin Oncol 20: 289-296, 2002.
30. Shimada K, Nakamura M, Anai S, De Velasco M, Tanaka M, Tsujikawa K, Ouji Y and Konishi N: A novel human AlkB homologue, ALKBH8, contributes to human bladder cancer progression. Cancer Res 69: 3157-3164, 2009.

31. Wu SS, Xu W, Liu S, Chen B, Wang XL, Wang Y, Liu SF and Wu JQ: Down-regulation of ALKBH2 increases cisplatin sensitivity in H1299 lung cancer cells. Acta Pharmacol Sin 32: 393-398, 2011.

32. Gao W, Li L, Xu P, Fang J, Xiao S and Chen S: Frequent downregulation of hABH2 in gastric cancer and its involvement in growth of cancer cells. J Gastroenterol Hepatol 26: 577-584, 2011.

33. Neta G, Brenner AV, Sturgis EM, Pfeiffer RM, Hutchinson AA, Aschebrook-Kilfoy B, Yeager M, Xu L, Wheeler W, Abend M, et al: Common genetic variants related to genomic integrity and risk of papillary thyroid cancer. Carcinogenesis 32: 1231-1237, 2011.

34. Calvo JA, Meira LB, Lee CY, Moroski-Erkul CA, Abolhassani N, Taghizadeh K, Eichinger LW, Muthupalani S, Nordstrand LM, Klungland A, et al: DNA repair is indispensable for survival after acute inflammation. J Clin Invest 122: 2680-2689, 2012.

35. Shimada K, Fujii T, Tsujikawa K, Anai S, Fujimoto K and Konishi N: ALKBH3 contributes to survival and angiogenesis of human urothelial carcinoma cells through NADPH oxidase and tweak/Fn14/VEGF signals. Clin Cancer Res 18: 5247-5255, 2012.

36. Casamassima A, Picciariello M, Quaranta M, Berardino R, Ranieri C, Paradiso A, Lorusso V and Guida M: C-reactive protein: A biomarker of survival in patients with metastatic renal cell carcinoma treated with subcutaneous interleukin-2 based immunotherapy. J Urol 173: 52-55, 2005.

37. Lamb GW, McMillan DC, Ramsey S and Aitchison M: The relationship between the preoperative systemic inflammatory response and cancer-specific survival in patients undergoing potentially curative resection for renal clear cell cancer. Br J Cancer 94: 781-784, 2006.

38. Karakiewicz PI, Hutterer GC, Trinh QD, Jeldres C, Perrotte P, Gallina A, Tostain J and Patard JJ: C-reactive protein is an informative predictor of renal cell carcinoma-specific mortality: A European study of 313 patients. Cancer 110: 1241-1247, 2007.

39. Yang J, Wezeman M, Zhang X, Lin P, Wang M, Qian J, Wan B, Kwak LW, Yu L and Yi Q: Human C-reactive protein binds activating Fcgamma receptors and protects myeloma tumor cells from apoptosis. Cancer Cell 12: 252-265, 2007.

40. Secchiero P, Rimondi E, di Iasio MG, Agnoletto C, Melloni E, Volpi I and Zauli G: C-Reactive protein downregulates TRAIL expression in human peripheral monocytes via an Egr-1-dependent pathway. Clin Cancer Res 19: 1949-1959, 2013. 